\title{
SWRO-PRO System in “Mega-ton Water System" for Energy Reduction and Low Environmental Impact
}

\author{
Masaru Kurihara * and Hiromu Takeuchi \\ Toray Industries, Inc., 2-1-1, Nihonbashi-muromachi, Chuo-ku, Tokyo 103-8666, Japan; \\ Hiromu_Takeuchi@nts.toray.co.jp \\ * Correspondence: Masaru_Kurihara@nts.toray.co.jp; Tel.: +81-3-3245-5716
}

Received: 26 September 2017; Accepted: 27 December 2017; Published: 9 January 2018

\begin{abstract}
Reverse osmosis (RO) membranes have been widely applied in seawater desalination (SWRO) and wastewater reclamation as the main desalination technology since 2000. SWRO plants face challenges to reduce energy consumption and brine disposal to lessen marine pollution. To tackle these challenges, a SWRO-PRO (Pressure Retarded Osmosis) System was proposed in the "Mega-ton Water System" project under the Japanese national project of the "Funding Program for World-Leading Innovative R\&D on Science and Technology" (FIRST Program). To reduce the energy consumption of the main SWRO plant, an innovative low-pressure SWRO membrane and a next generation energy recovery device (ERD) were developed by the "Mega-ton Water System" project. In addition to this research and development, a new membrane process has been proposed and confirmed as a low-pressure multi-stage SWRO (LMS). A brine conversion two-stage SWRO system was invented 20 years ago, and has been in operation for over 15 years. Application of the SWRO membrane process to actual commercial plants was an important research theme. The low-pressure multi-stage SWRO System (LMS) was an innovative method of introducing a low-pressure membrane and the membrane element in the pressure vessel was designed to avoid heavy fouling of lead elements. As a result of these developments at mega-ton scale SWRO plants, a 20\% energy reduction was possible in the SWRO system of the "Mega-ton Water System". In the development of the PRO process, a PRO hollow fiber membrane module with a maximum $13.3 \mathrm{w} / \mathrm{m}^{2}$ of membrane power density using a 10-inch module was established at a prototype PRO plant. Thus, a 30\% energy reduction was possible using the SWRO-PRO System in the "Mega-ton Water System" at mega-ton scale SWRO plants. The brine disposal problem was also solved by this system.
\end{abstract}

Keywords: Seawater Reverse Osmosis (SWRO); Pressure Retarded Osmosis (PRO); Low Pressure Seawater Reverse Osmosis Membrane; “Mega-ton Water System”; Brine Conversion Two-stage RO Seawater Desalination System; Low Pressure Multi-Stage System (LMS); Energy Recovery Device (ERD); PRO membrane

\section{Introduction}

Seawater desalination went into operation in the 1960s as national research of the United States, and the distillation process became commonly used in actual plants in the 1970s. However, since 2000, the energy saving reverse osmosis membrane process has surpassed the distillation process and has rapidly spread as plants have become bigger, as shown in Figure 1 (produced by the authors based on data) [1]. The Online Cumulative Capacity $\left(\mathrm{m}^{3} /\right.$ day) of RO is higher than that of MSF and MED. The growth rate of RO is also very high compared with that of MSF and MED. The cumulative number of MSF, MED and RO plants is increasing. The large number of RO plants means the average size of RO plants are still small compared with MSF and MED. 


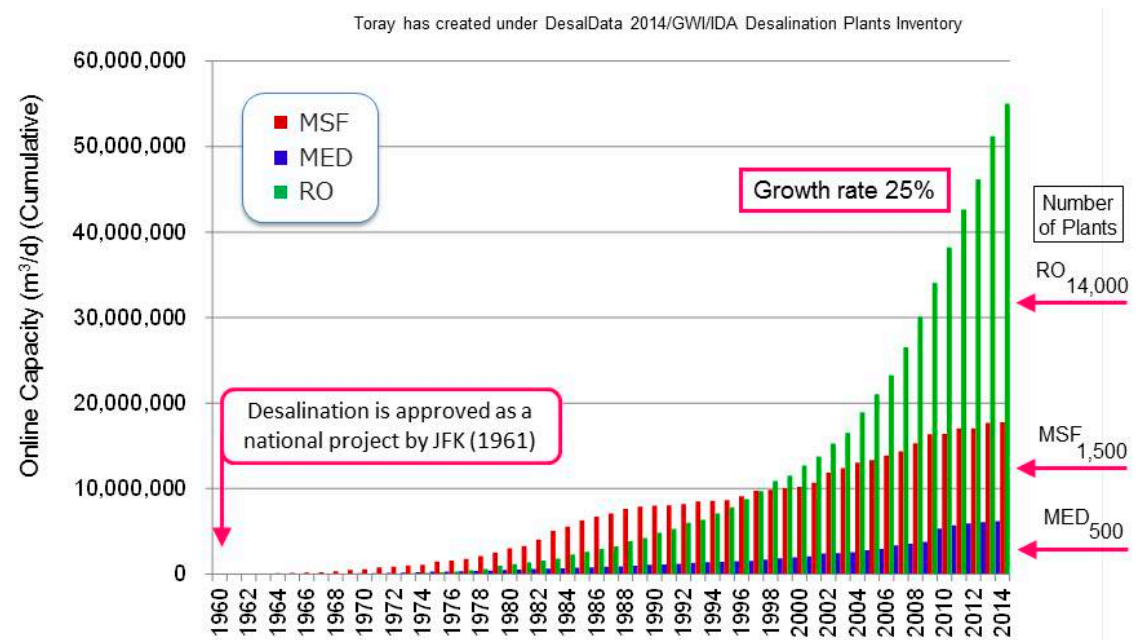

Figure 1. Transition of the technology from distillation to membrane and expansion of global desalination market.

Considering the increase in the population and economic development, the desalination market is growing rapidly (Figure 1). The size of desalination plants is increasing, and ultra large plants handling mega-tons per day $\left(1,000,000 \mathrm{~m}^{3} /\right.$ day) will be required by 2020 [2], as shown in Figure 2. To solve the global water shortage problem, plants have been using the reverse osmosis membrane process, which has been rapidly spreading in recent years, since around 1970. After that, enlargement of the plant scale has progressed, and, since 2000, they have grown to exceed 100,000 $\mathrm{m}^{3}$ /day (corresponding to the amount of water necessary for about 400,000 people on average in developed countries).

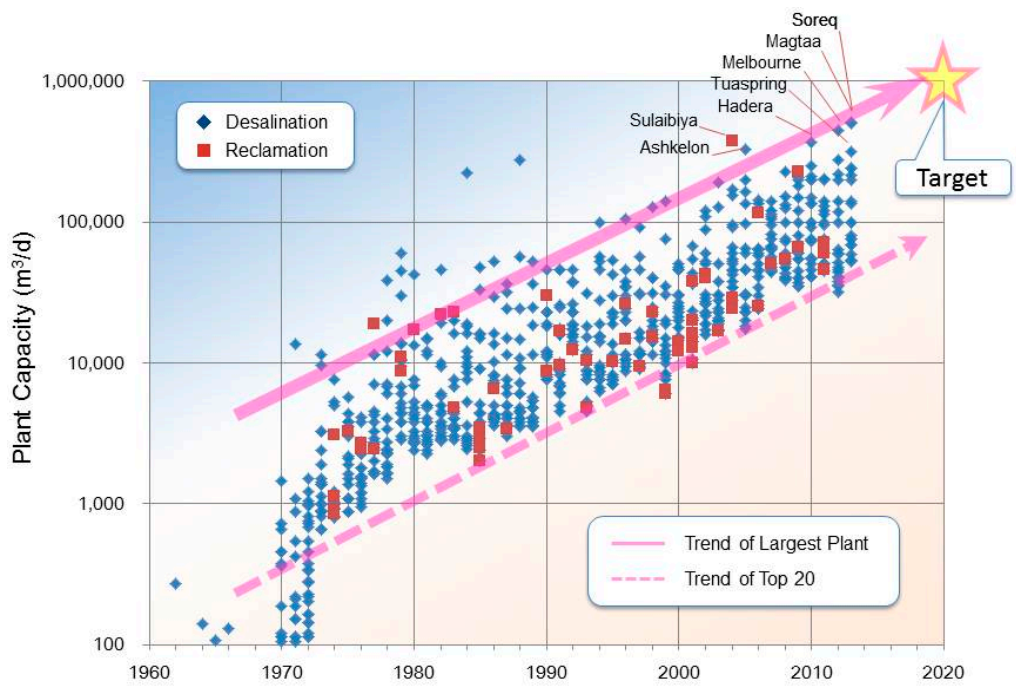

Figure 2. Change in Reverse osmosis (RO) plant size of desalination and reclamation.

The largest plant capacity and the top 20 largest plants are plotted since 1970 in the area of desalination and wastewater reclamation RO plants. Recent large desalination plants are in Ashkelon (Israel), Hadera (Israel), Tuasspring (Singapore), Melbourne (Australia), Magtaa (Algelia), and Soreq (Israel). The largest recent wastewater reclamation plant is in Sulaibiya (Kuwait). This shows that desalination and wastewater reclamation plants are now distributed globally. The technological requirements in the 21st century for sustainable desalination are listed in Figure 3 [2]. 


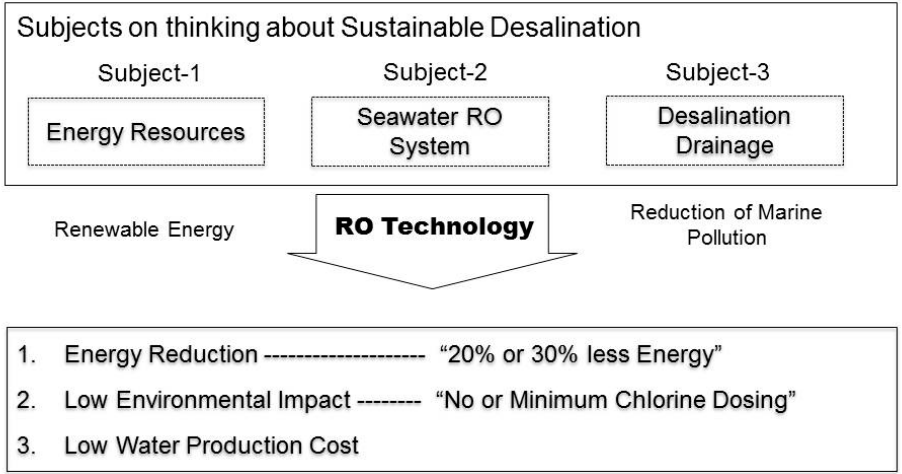

Figure 3. Technology requirements in the 21st century for sustainable desalination.

Although three subjects are very important, the energy resources of Subject 1 are beyond the scope of this project. Subject 2 is the heart of the SWRO system, and the following four factors are key to SWRO technology.

(1) Energy saving ( $20 \%$ or $30 \%$ less energy)

(2) Low environmental impact (no or minimum chlorine dosing)

(3) Low water production cost

(4) Reliable plant operation

In addition to this, Subject 3, desalination drainage, is important to reduce marine pollution.

There is rising awareness of the need to preserve the environment, and the ecological influence of discharged chemical-treated seawater from desalination plants is a concern, thus the chemical consumption at the desalination plant should be as low as possible and the brine concentration should be similar to that of the feed seawater [3].

This research used Japan's national research "FIRST Program" to promote broad research on core water treatment technologies and the "Mega-ton Water System", including element technologies and system technologies, to advance basic technologies and strengthen weak system technologies [2,4].

To establish the three requirements shown in Figure 3, total solutions are required in sustainable desalination, such as the combination of membrane technology, membrane processing technology, energy recovery devices (ERD) and bio-technology for reliable operations.

The specific research themes and the missions of the "Mega-ton Water System" are the four themes of core technology and the two themes of system technology shown in Table $1[2,4,5]$.

Table 1. Research Themes and Missions.

\begin{tabular}{|c|c|c|c|c|c|}
\hline No. & $\begin{array}{ll}\text { Theme } & \text { Mission } \\
\end{array}$ & $\begin{array}{l}\text { Energy } \\
\text { Saving }\end{array}$ & $\begin{array}{l}\text { Low Environmental } \\
\text { Impact }\end{array}$ & $\begin{array}{c}\text { Low Water } \\
\text { Production Cost }\end{array}$ & $\begin{array}{l}\text { Plant Operation } \\
\text { Reliability }\end{array}$ \\
\hline 1 & $\begin{array}{l}\text { Innovative Low-Pressure } \\
\text { SWRO Membrane }\end{array}$ & $X$ & $X$ & $X$ & \\
\hline 2 & $\begin{array}{l}\text { Next Generation Energy } \\
\text { Recovery Device (ERD) }\end{array}$ & $X$ & $X$ & $x$ & $X$ \\
\hline 3 & $\begin{array}{l}\text { Low-pressure Multi-stage } \\
\text { SWRO System (LMS) }\end{array}$ & & & $X$ & $X$ \\
\hline 4 & $\begin{array}{l}\text { Pressure Retarded } \\
\text { Osmosis (PRO) }\end{array}$ & $X$ & $X$ & $X$ & \\
\hline 5 & $\begin{array}{l}\text { High Durability } \\
\text { High-Pressure Resin Pipe }\end{array}$ & & & $X$ & $X$ \\
\hline 6 & $\begin{array}{l}\text { Bio-fouling Monitoring } \\
\text { Technology (mBFR) }\end{array}$ & & $X$ & $X$ & $X$ \\
\hline
\end{tabular}

Note: X means that it is connected with Theme and Mission. 
First, an innovative low pressure SWRO membrane is important for saving energy. This theme contributes to the low environmental impact and low water production cost as a result of saving energy.

Second, next generation energy recovery devices (ERD) are necessary for saving energy and contributing to low environmental impact and low water production cost, as well as improved plant operation reliability.

Third, a low-pressure multistage SWRO system (LMS) optimizes the RO plant system by effectively utilizing the features of the two energy-saving factors mentioned above, which contribute to low water production costs and improved plant operation reliability.

Fourth, pressure retarded osmosis (PRO) can recover the energy of concentrated seawater and reduce the environmental impact at the same time, and as a result contribute to low water production cost.

Fifth, the development of highly durable high-pressure resin pipes involves plasticizing high-pressure metal piping, which is expensive, but can reduce corrosion problems. This contributes to low water production cost and improved plant operation reliability.

Lastly, bio-fouling monitoring technology (mBFR), which is essential for solving the bio-fouling problem of RO plants, contributes to low environmental impact and low water production cost by no or minimum chlorine dosing. This is an important technology for improving the reliability of plant operation.

Each research theme was undertaken by the following organizations:

1. Innovative low-pressure SWRO membrane: Mainly researched by Toray;

2. Next generation energy recovery device (ERD): Mainly researched by Ebara Corporation;

3. Low-pressure multistage SWRO system (LMS): Mainly researched by Hitachi;

4. Pressure retarded osmosis (PRO): Mainly researched by Kyowakiden Industry;

5. High durability high-pressure resin pipe: Mainly researched by Asahi Yukizai Corporation;

6. Bio-fouling monitoring technology (mBFR): Mainly researched by Toray.

The relationship between the Theme and Mission in Table 1 become very clear. Energy saving is related to Themes 1, 2 and 4. Low environmental Impact is related to Themes 1, 2, 4 and 6. Low water production cost is related to Themes 1-6. Plant operation reliability is related to Themes 2, 3, 5 and 6. Especially, low water production cost is very a complex matter to discuss generally. Thus, the "Mega-ton Water System" project has been involved in cost reduction using advanced technology. The authors do not discuss each plant; instead, plant size, operating pressure reductions, energy recovery increase by new generation ERD, the optimized SWRO system by LMS, energy recovery by $\mathrm{PRO}$, high durability high pressure resin pipe, and less chemical by no chlorine and sodium bisulfite are included. It was very difficult to cite the cost comparison done by others in the last years because the premise of cost condition is very different, even though we have many announcements.

The outputs of the "Mega-ton Water System" with its six indispensable technologies for the 21st century are summarized in Figure 4 [2,5-7]. 


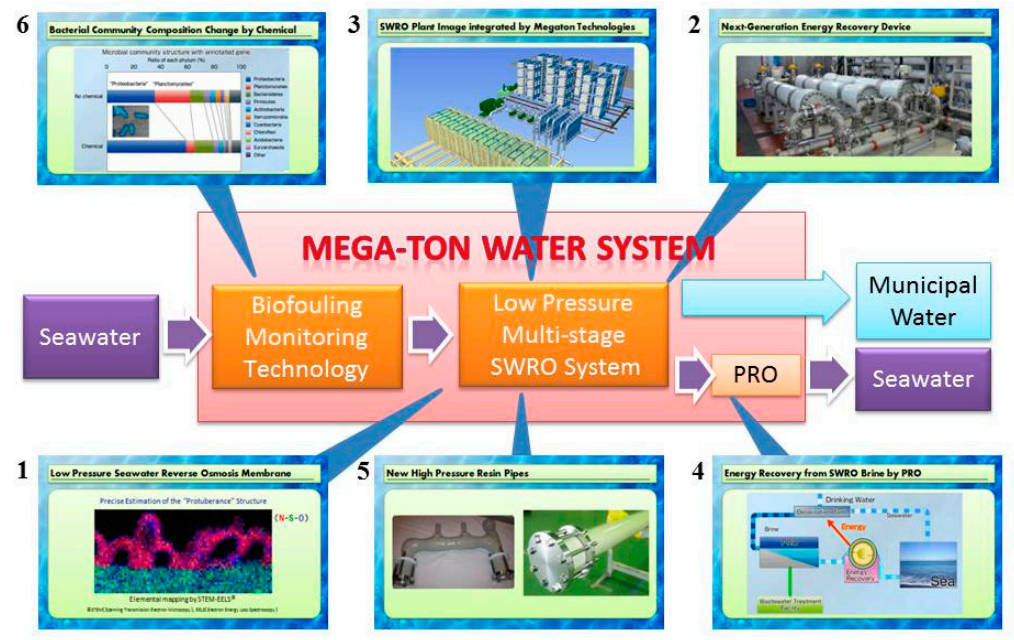

Figure 4. Outputs of the "Mega-ton Water System" with its six indispensable technologies for the 21st century.

\section{Research Results and Discussion}

\subsection{Innovative Low Pressure SWRO Membrane of the "Mega-ton Water System"}

\subsubsection{Requirement for Energy-Saving and Water Quality Improvement}

Energy reduction and improvement of water quality are the two major subjects in SWRO desalination. The average energy consumption in SWRO plants has been reduced to $40 \%$ as a total plant and one fourth in the case of 1 st RO pass consumption over the last 40 years, as shown in Figure 5 [8]. This is a result of the remarkable technical advances in membranes, pumps and energy recovery devices. Technical progress to reduce energy consumption further, for example low-pressure operation membrane and high efficient energy recovery device are still required.

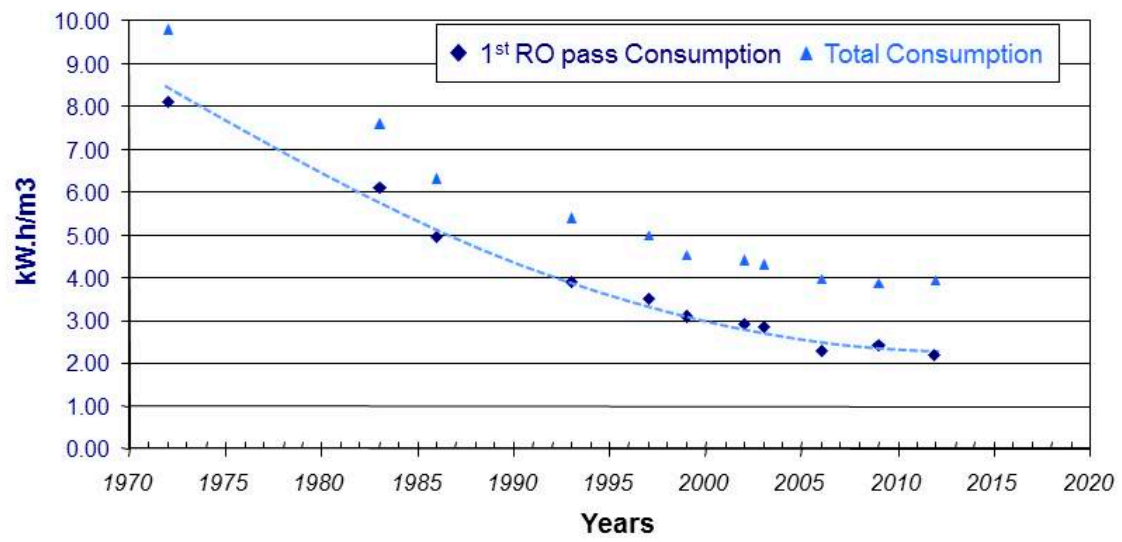

Figure 5. Trends of energy reduction in seawater RO.

As for water quality, the regulation value of salts disinfection by-products (DBPs) and boron concentration are considered depending on whether the water is for drinking or irrigation use.

Although the ideal crosslinked fully aromatic polyamide SWRO membrane should have both high water permeability and high solute removal performance, there is usually a trade-off between increased water permeability and decreased solute rejection rate. However, when a pore in an RO membrane, which is a space within polymers, is assumed, the performance of the RO membrane must be controlled by size and quantity. Namely, solutes in the water are excluded by pore size, 
and the water permeability depends on the quantity of pores. To enhance performance, scientific research on the molecular structure and solute transport mechanism in an RO membrane is necessary. Schematic diagram of water permeation through the protuberance of the RO membrane is shown in Figure 6 [5-7].

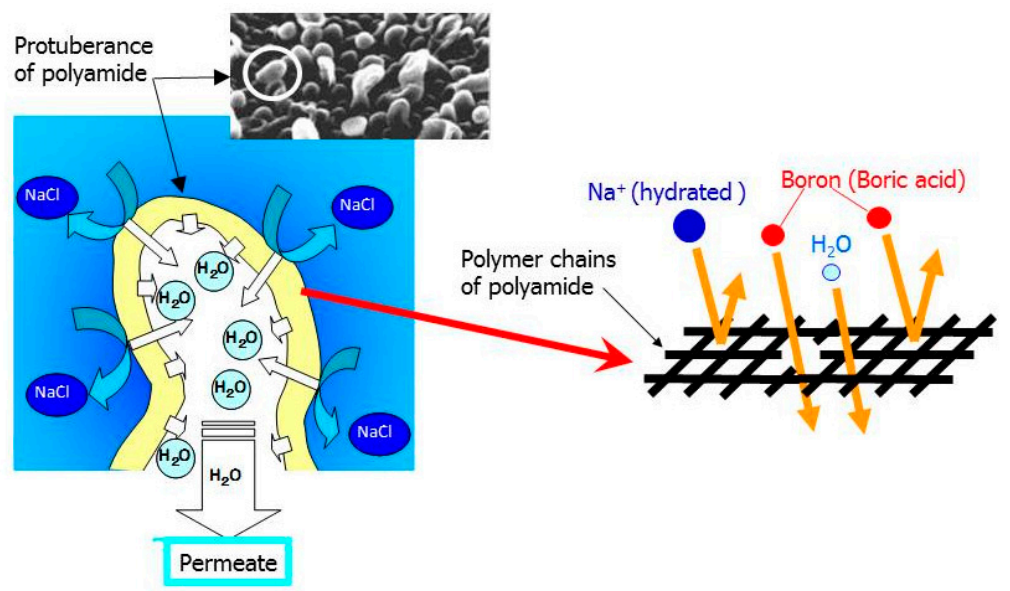

Figure 6. Schematic diagram of salt removal and water permeation through the protuberance.

\subsubsection{Innovative Low-Pressure SWRO Membrane}

To develop innovative low-pressure SWRO membranes aiming at energy reduction, evaluation of the pore size of the $\mathrm{RO}$ membrane functional layer and accurate structural evaluation of the fold are necessary.

Using a conventional scanning electron microscope (SEM), only the information shown in Figure 7 (upper left) was obtained, and the fold structure could not be determined accurately. In this research, an improvement was made to the conventional pretreatment method of the RO membrane structure analysis, and a new pretreatment method that can be analyzed and evaluated while maintaining the membrane surface morphology in the wet state of the membrane was developed. As a result, it has become possible to capture the fold structure accurately as shown in Figure 7 (upper right) [5-7,9].

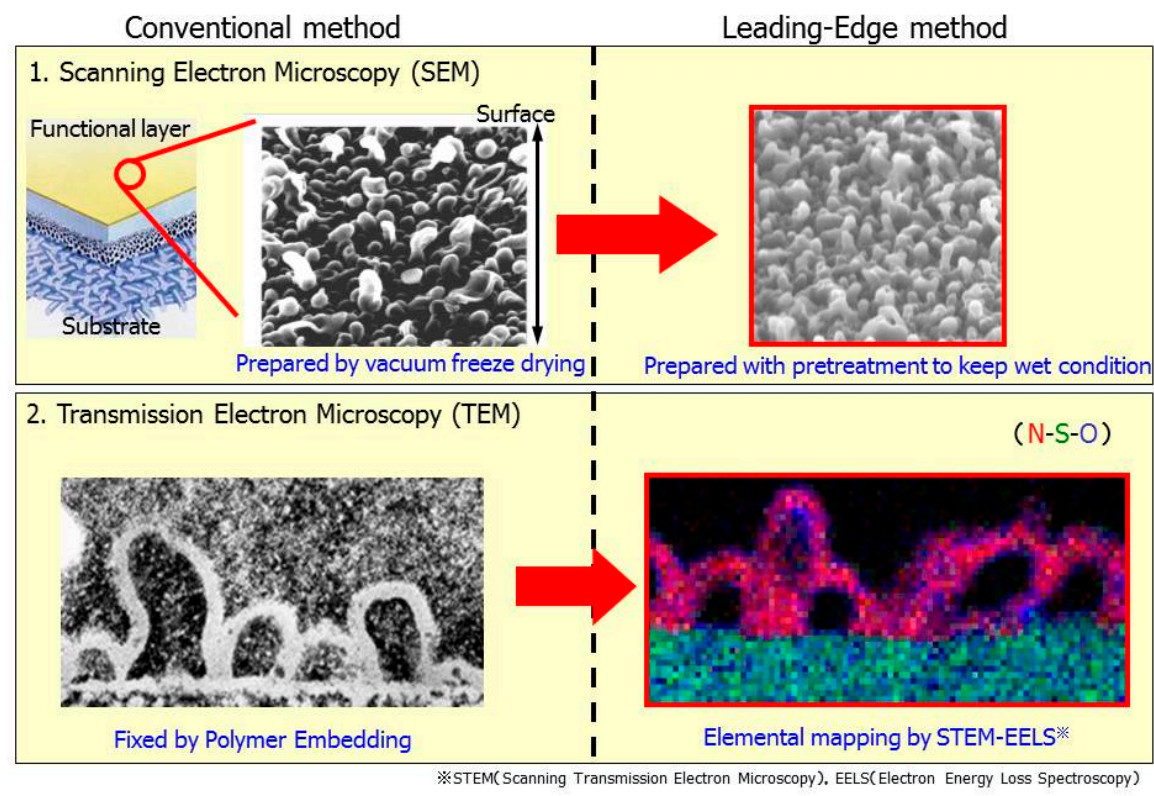

Figure 7. Precise structure of protuberance in "Mega-ton Water System" project. 
By applying the new pretreatment method and adding technology for evaluating basic analysis of the RO membrane structure using a transmission electron microscope (TEM) (conventional process (Figure 7) (lower left)), it has become possible to perform mapping analysis on nitrogen atoms derived from polyamide membranes. This has made it possible to clarify that the surface of the fold structure is a true polyamide layer (Figure 7) (lower right) [5-7,9].

Since the RO membrane structure analysis technology described above made it possible to specify the factors of an ultrathin membrane fold structure related to the RO membrane performance, to obtain guidelines for the design of an RO membrane whose fold structure was captured in three dimensions as well as obtain an innovative low-pressure SWRO membrane capable of energy saving, it was found that optimum pore size control of the RO membrane functional layer and optimization of the surface area and membrane thickness of the folds were important.

As a result, the basic membrane forming technology on a bench scale was established, and the forming of an energy reduction type low pressure SWRO membrane that can operate at a significantly lower pressure than the conventional RO membrane was a success (Figure 8) [5-7,9].

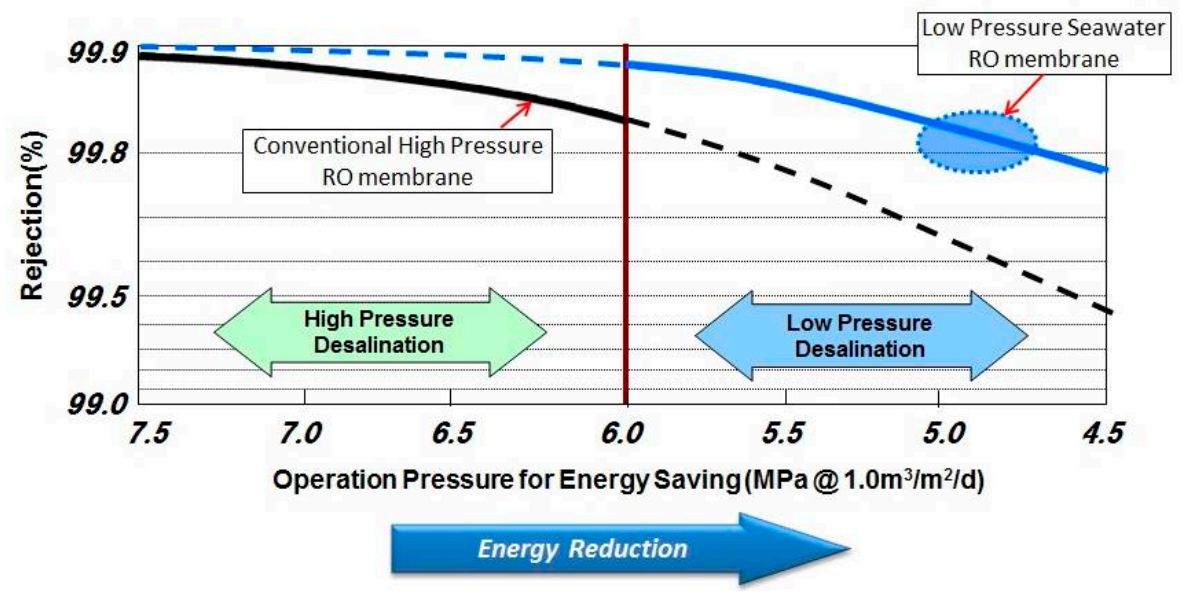

Figure 8. Comparison of conventional high-pressure Seawater Reverse Osmosis (SWRO) membrane and low-pressure SWRO membrane.

The operation pressure for obtaining the same permeation flux and the same salt removal rate is higher than $6 \mathrm{MPa}$ in conventional high-pressure desalination. However, the low-pressure desalination in this research makes it possible to lower the pressure to $5 \mathrm{MPa}$, thus greatly contributing to energy saving (Figure 8).

\subsection{Next Generation Energy Recovery Device (New ERD)}

Most of the energy required for a seawater desalination plant using the RO membrane is applied to high-pressure water supplied to the RO membrane and accounts for about 70\%. Therefore, to save energy, it is important to reduce the amount of water supplied, improve the efficiency of the high-pressure pump and improve the recovery rate of the energy contained in the concentrated water. In particular, while concentrated water-containing energy recovery devices (ERD) have been thoroughly considered since the start of the practical use of the $\mathrm{RO}$ seawater desalination process, the turbine-type ERD (conversion efficiency 60-80\%) was brought to the market first and by 2000 it had produced many achievements. Later, the isobaric-type ERD (conversion efficiency 92-97\%) was increasingly installed into new seawater desalination plants since it has a superior recovery rate $[10,11]$.

This isobaric-type ERD consists of a method of employing a rotation rotor and a piston built-in method. Based on this isobaric-type ERD method, by making further improvement, this research aimed to develop a next generation energy recovery device (New ERD) that is suitable for large plants and gives high performance and high reliability. 
The main characteristics are as follows:

(1) It adopts a piston-less chamber so there is no wear to parts.

(2) It prevents over-flush, which reduces the waste of pretreatment water, as well as minimizes the mixture of pretreatment water and concentrated water.

(3) Adoption of the one-chamber, one-control valve form enables high-precision control, which does not generate internal leakages and is resistant to contamination.

To embody the characteristics above, a vertical chamber was adopted (refer to Figure 9 [11]), and, by establishing a special rectification structure at the edge of the chamber, stable energy exchange between the concentrated water and the pretreatment water became possible.

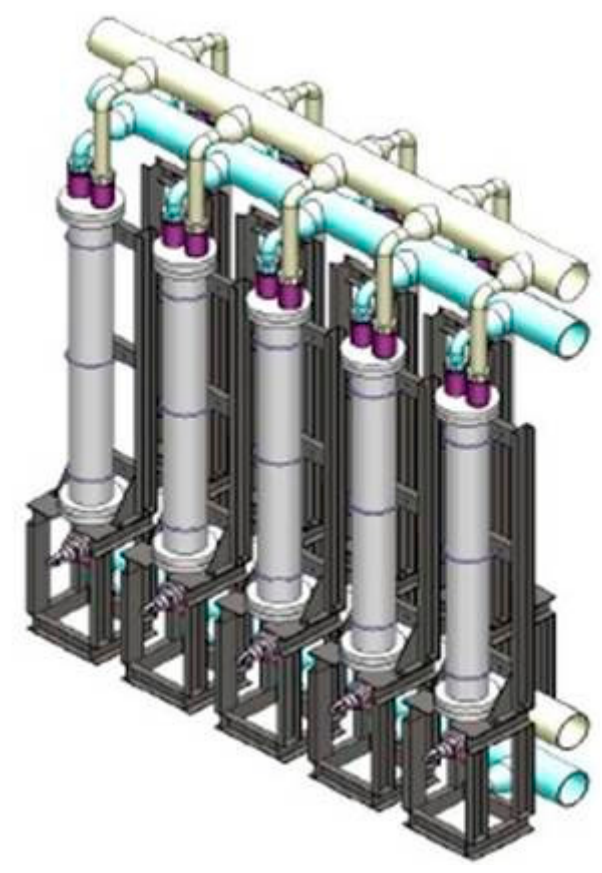

Figure 9. Next generation Energy Recovery Device (ERD).

Therefore, as shown in Table 2, while the conventional isobaric-type ERD required 6-7\% extra energy compared to the ideal ERD, this method made it possible to reduce the extra energy consumption by $2.5 \%$. An installation image of ERD in the "Mega-ton Water System" is shown in Figure 10 [11].

Table 2. Comparison of ERD Key Performance.

\begin{tabular}{ccccc}
\hline Key Items & Ideal ERD & New ERD & $\begin{array}{c}\text { Conventional ERD } \\
\text { with Over-Flush }\end{array}$ & $\begin{array}{c}\text { Conventional ERD } \\
\text { without Over-Flush }\end{array}$ \\
\hline Energy Recovery Effectiveness & $100 \%$ & $98.3 \%$ & $96.4 \%$ & $96.4 \%$ \\
Mixing & $0.0 \%$ & $1.3 \%$ & $2.5 \%$ & $6.0 \%$ \\
Over-Flush & $0.0 \%$ & $0.0 \%$ & $5.0 \%$ & $0.0 \%$ \\
Normalized S.E.C. for RO core process & 1.000 & 1.025 & 1.059 & 1.069 \\
\hline
\end{tabular}




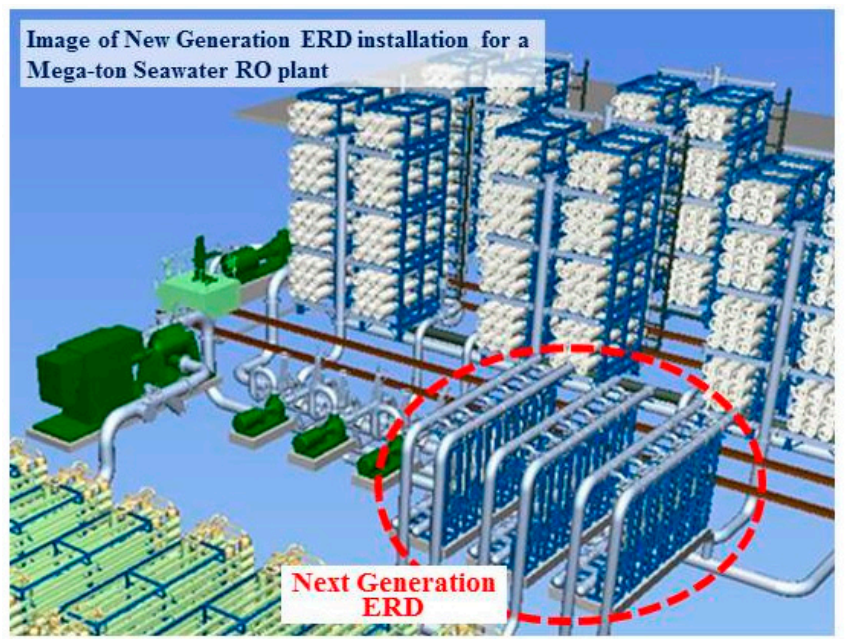

Figure 10. Next generation ERD and an image of its installation for a mega-ton seawater RO plant.

\subsection{Low-Pressure Multi-Stage SWRO System (LMS) of the "Mega-ton Water System"}

In the development of RO technology, continuous research is required on membranes and the membrane processes.

\subsubsection{Brine Conversion Two-Stage SWRO System}

A low-cost seawater desalination system called the Brine Conversion System (BCS) was developed 20 years ago by the author's group [12], as shown in Figure 11, which provides a 60\% recovery rate. The concentrated seawater (5.8\% of salt concentration) from the first stage RO modules is pressurized to $8-10 \mathrm{MPa}$ by a pressure booster, then the concentrate is supplied to the second stage RO modules. Additional fresh water is obtained from the second stage, and the feed water is finally concentrated to approximately $8.7 \%$ salt concentration. A $60 \%$ recovery rate in total can be obtained, of which $40 \%$ comes from the first stage and a further $20 \%$ comes from the second stage.

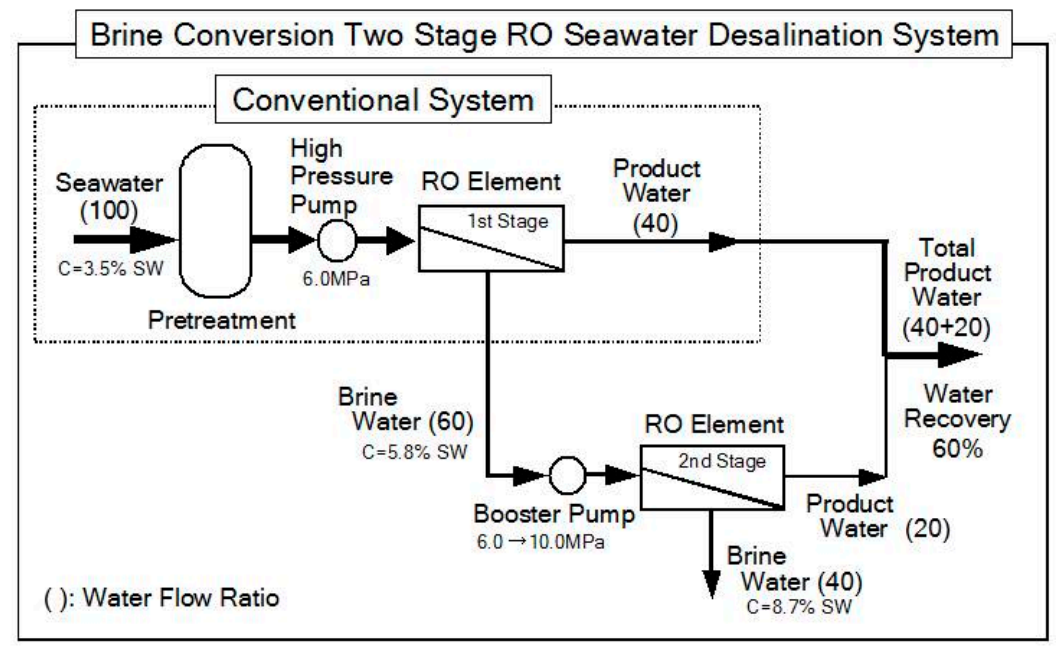

Figure 11. Brine conversion two-stage system (BCS).

To achieve $60 \%$ recovery in a RO seawater desalination system, the RO membrane element must be durable under very severe operating conditions with $10 \mathrm{MPa}$ of high pressure and $5.8 \%$ of high feed water concentration. Toray developed a high-pressure durable BCM element.

The advantages of the BCS system compared with the conventional system are as follows: 
a. Plant installation space can be reduced to $2 / 3$.

b. Plant capacity is easily expanded to 1.5 times by only adding BCS second stage into the conventional plant.

c. Disposed concentrated brine water is reduced to $2 / 3$.

Therefore, the BCS is a useful way of reducing the footprint, power and cost of a SWRO desalination plant.

The BCS system has now been in operation in actual plants such as in Trinidad and Tobago $\left(136,000 \mathrm{~m}^{3} /\right.$ day) and in the Canary Islands (14,000 $\mathrm{m}^{3} /$ day) for over 15 years.

This two-stage SWRO system is an important research theme of the SWRO membrane process $[13,14]$.

\subsubsection{Low-Pressure Multi-Stage SWRO System (LMS)}

Our research project uses the world's first high-performance innovative low-pressure SWRO membrane described in Sections 2.1.2 and 2.2 (New ERD) [11] as basic element technologies, and we developed the LMS to prevent fouling of the RO membranes and to enable RO elements to be utilized effectively in order to enhance the reliability of plant operation.

This system makes it possible to greatly reduce the equipment cost, operation cost and energy required by enabling the enlargement of equipment parts, enlargement of the system and downsizing of water intake/pretreatment facilities (30\% reduction of the installation area) by recovery rate enhancement.

The LMS incorporating low-pressure SWRO membranes and new ERD under conditions of a high-recovery rate, which will reduce the facility costs and the supply of seawater, is a system that derives the maximum performance of the $\mathrm{RO}$ membranes. A comparison between the conventional system flow with a $45 \%$ recovery rate and megaton system (LMS) flow with a $60 \%$ recovery rate is shown in Figure 12 [15].

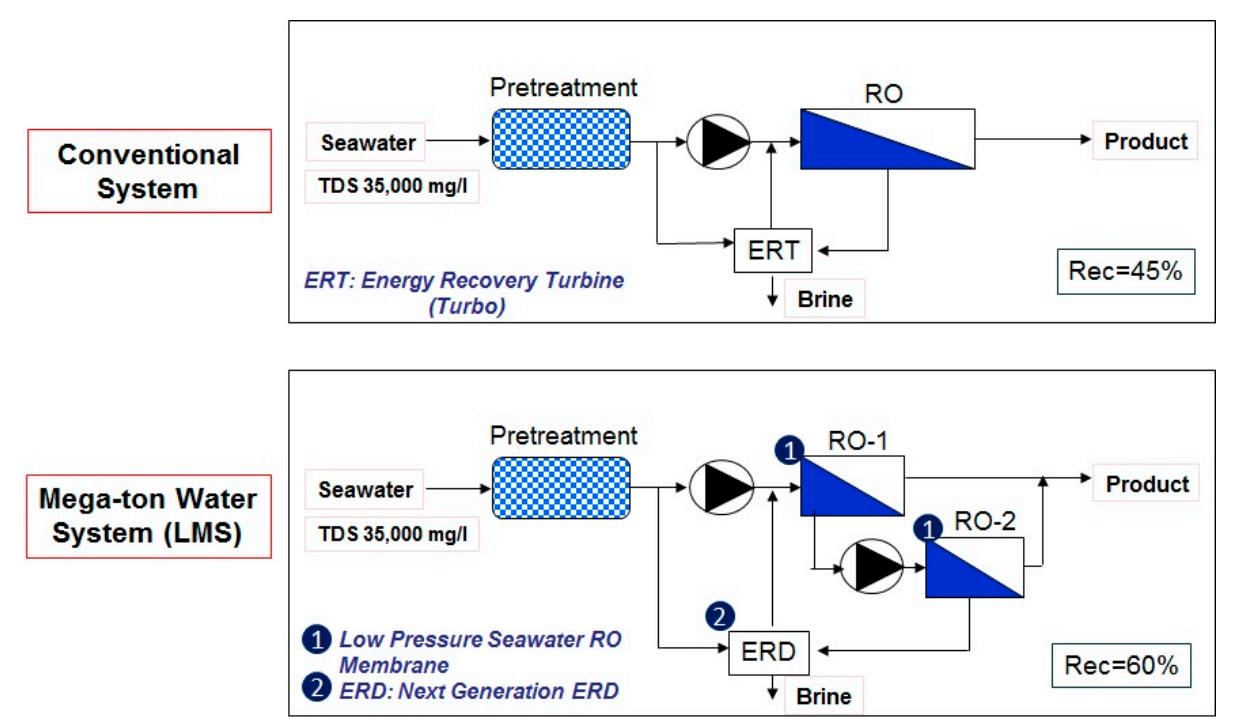

Figure 12. Comparison of flow diagram for conventional Seawater Reverse Osmosis (SWRO) system and "Mega-ton Water System" (Low Pressure Multi-Stage System (LMS)).

As it is possible to reduce the volume of seawater intake, it is possible to reduce the pretreatment facility capacity and installation area (by about 30\%).

The "Mega-ton Water System", combining the research results described above with the latest high-efficiency, high-pressure pump technology (manufactured by Ebara Corporation), made it 
possible to dramatically reduce energy consumption [11,15]. The "Mega-ton Water System" enables energy savings of 20\% compared to conventional seawater desalination systems at technology 2010 using turbocharger-type ERD, as shown in Figure 13 [7,11,15].

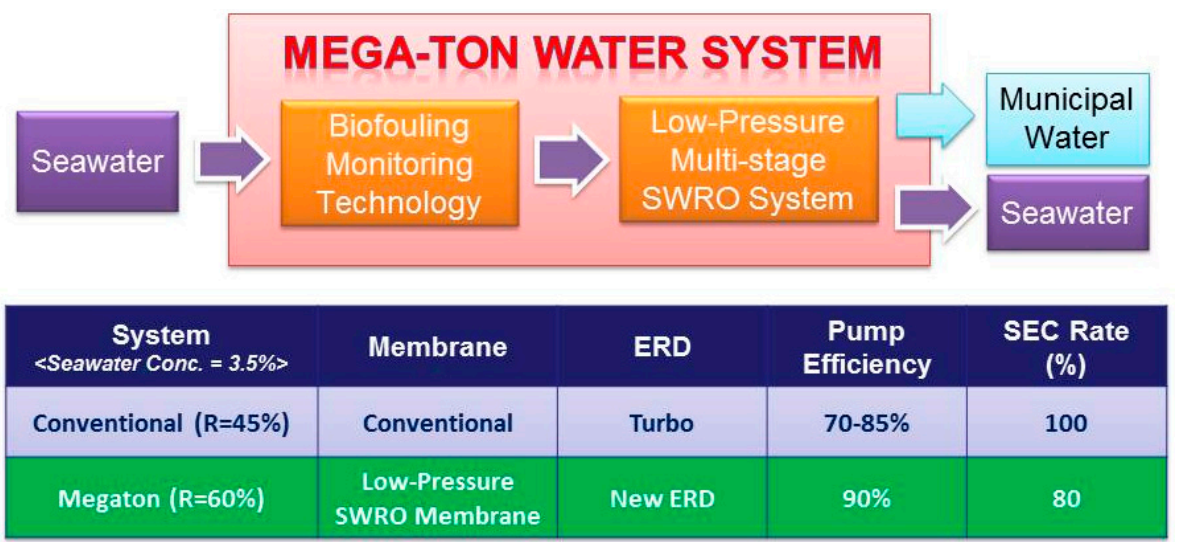

Figure 13. SEC Rate (\%) comparison of conventional SWRO and Mega-ton System (LMS).

Although Miguel Sanz has reported the historical trends of the energy consumption of the total plant and the 1st RO pass, as shown in Figure 5 [8], in the "Mega-ton Water System" project, the target value of energy consumption as total plant under TDS 35,000 $\mathrm{mg} / \mathrm{L}$ seawater concentration was set to $3.00 \mathrm{~kW} \cdot \mathrm{h} / \mathrm{m}^{3}$ or less. In this case, it is possible to reduce energy by $20 \%$ compared with the conventional system.

\subsection{SWRO-PRO System of "Mega-ton Water System"}

Pressure Retarded Osmosis (PRO), proposed by Loeb in 1975 [16] and 1976 [17], is a method of recovering the concentration difference (osmotic pressure) of energy using a separation membrane and is also called osmotic pressure power generation or salt concentration difference power generation since the energy can be recovered as electrical energy $[18,19]$. This energy is expected to be new renewable energy because it uses a highly stable energy source instead of a time-dependent energy source such as solar or wind power. However, there are technological challenges to overcome with PRO such as the improvement of the membrane permeation flux and fouling control because it uses a separation membrane.

Sarp [20] summarized the current status and prospect of PRO, and described two cases of applying PRO:

(1) Starkraft in Norway is an example of energy production from seawater-river water [21];

(2) The "Mega-ton Water System" project in Japan is an example of SWRO-treated waste water:

Case (1) is now suspended due to the poor membrane performance: failed to reach the target [19].

Case (2) [22,23].

In the "Mega-ton Water System", the concentrated seawater of a seawater desalination plant and treated discharge water of municipal sewage were used as the raw water. The aim was to reduce the environmental impact by discharging concentrated seawater into the sea as well as to recover the energy of the concentration difference between the two types of water.

In this research, this PRO technology (system) is to be added to the seawater desalination system according to the environmental needs, and the overall flow is shown in Figure 14 [22].

This research conducted various tests at a prototype plant (DS: $460 \mathrm{~m}^{3} /$ day, FS: $420 \mathrm{~m}^{3} /$ day). As a result of a prototype plant test using a PRO module (CTA hollow fiber with a diameter of 10-inch) available for actual devices, it turned out that practical use is possible by the data on the obtained applied pressure and power density. In addition, as a result of a long-term operation test, various 
investigations into the operational conditions meeting both fouling control and reduction of associated required power proved that the combination of the ultrafiltration (UF) membrane and chemical treatment enables stable operation. The SWRO-PRO system flow is shown in Figure 15 [22-24].

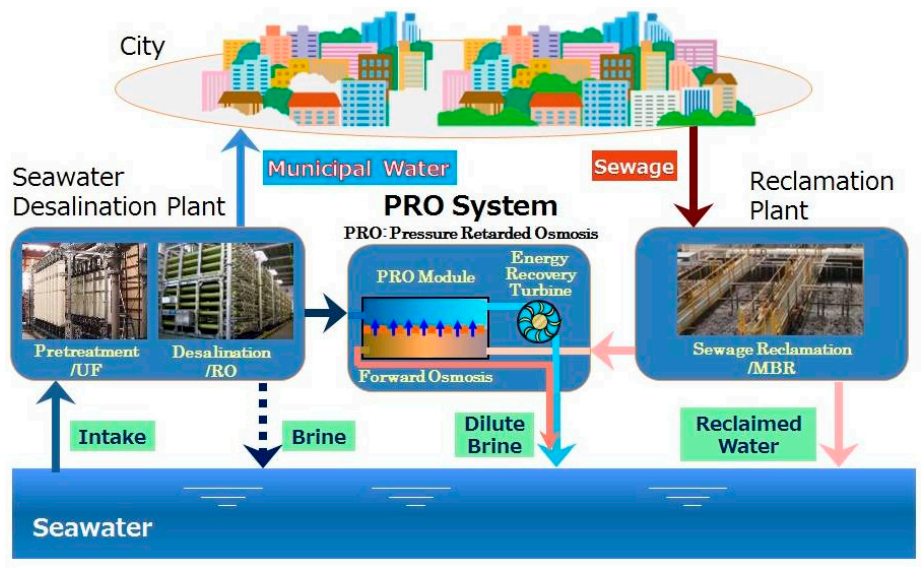

Figure 14. SWRO-PRO System.

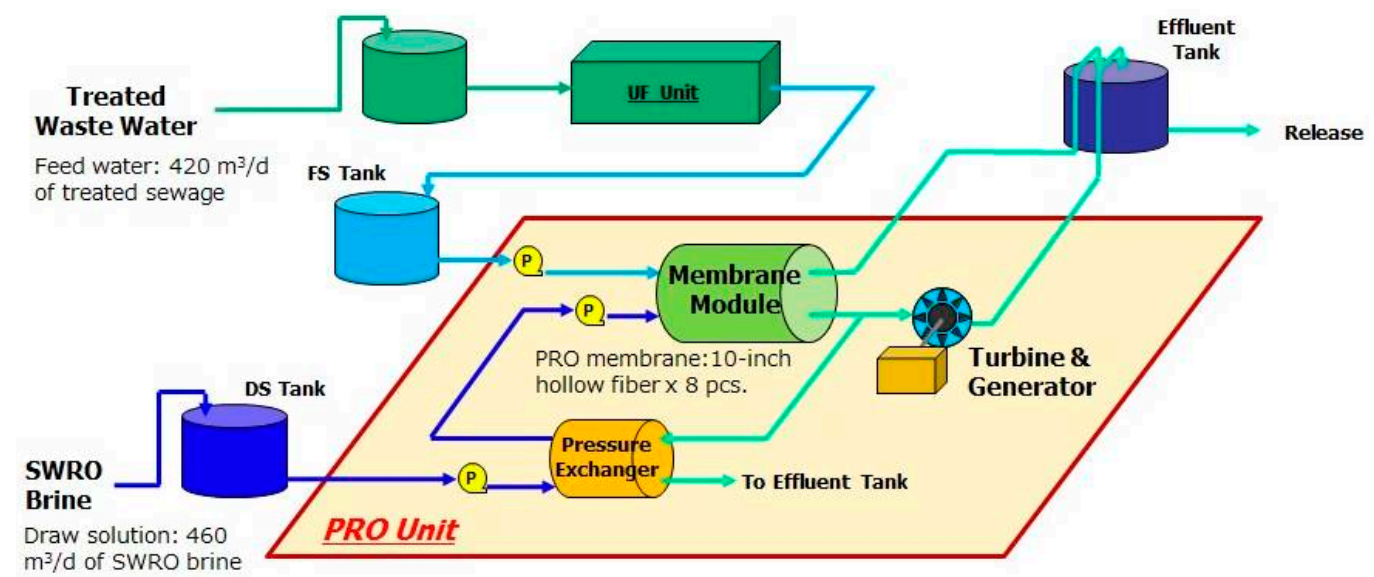

Figure 15. SWRO-PRO system flow.

The prototype plant achieved $13.3 \mathrm{~W} / \mathrm{m}^{2}$ of the maximum membrane power density per surface area using 10-inch membrane modules. On the other hand, the lab-scale plant showed $17.1 \mathrm{~W} / \mathrm{m}^{2}$ with a five-inch module, as shown in Figure 16 [22-24].

Long-term test operations at the PRO prototype plant were carried out over one year, as shown in Figure 17. The osmotic flow rate through the membrane was found to depend on the temperature, which varied seasonally as with conventional membranes. There was a slight decline in the osmosis flow rate between the beginning and one year after the test launch, even though it continued to use the same membrane modules. This means that we successfully produced fresh water from the treated waste water of sufficient quality for the PRO system, employing a conventional pre-treatment method and judged that commercial scale operation would be possible for long periods.

The calculation results of the demonstration operational results showed that installing a SWRO-PRO system reduces electricity consumption per unit necessary to produce water by $10 \%$ at mega-ton class $\left(1,000,000 \mathrm{~m}^{3} / \mathrm{d}\right.$ scale) water desalination facilities.

Energy savings of $30 \%$ in total, including energy savings of $20 \%$ with the SWRO of the "Mega-ton Water System" described in Section 2.3 are possible in the comparison with conventional seawater desalination system at technology 2010 (Figure 18) [5,22-24]. 


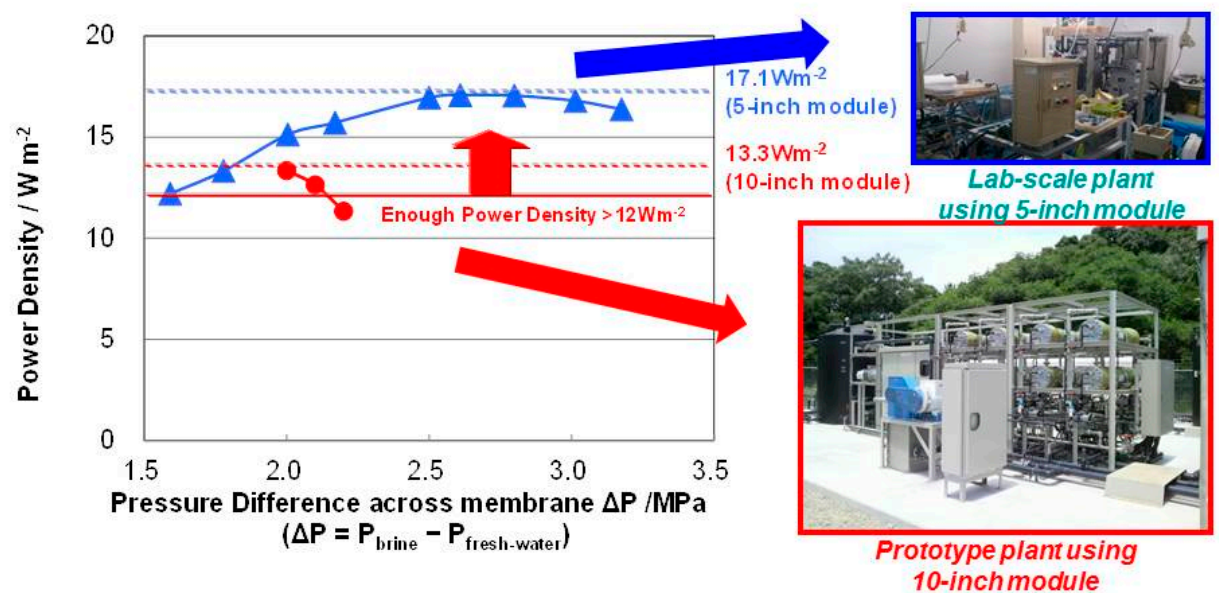

Figure 16. Achieved power density at prototype plant and lab-scale plant.

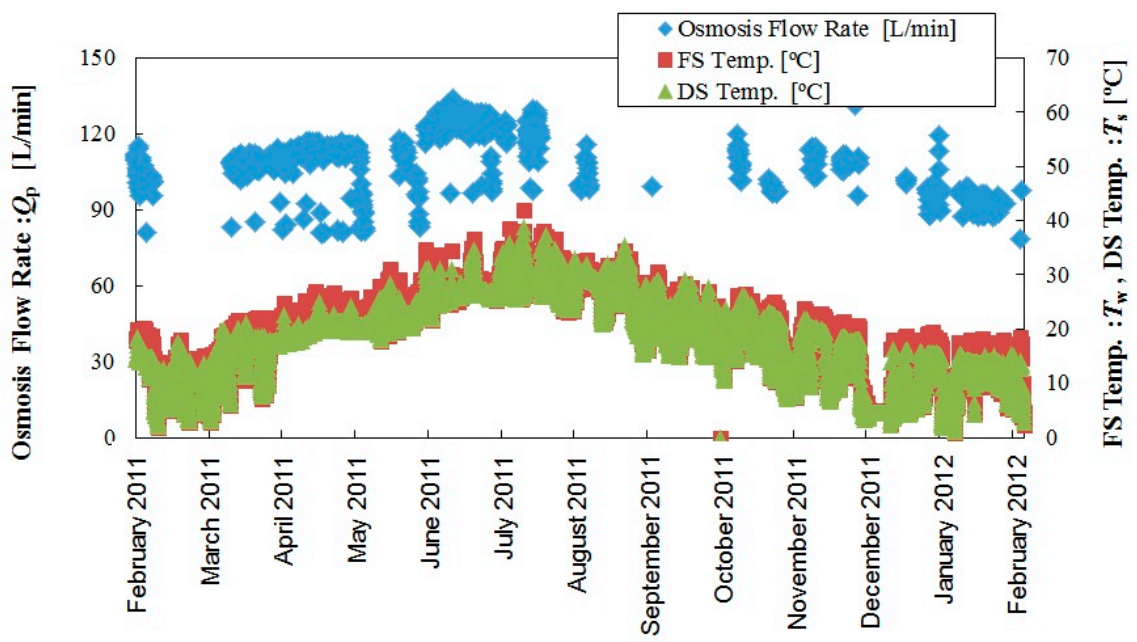

Figure 17. Long-term Prototype PRO Plant operation over one year.

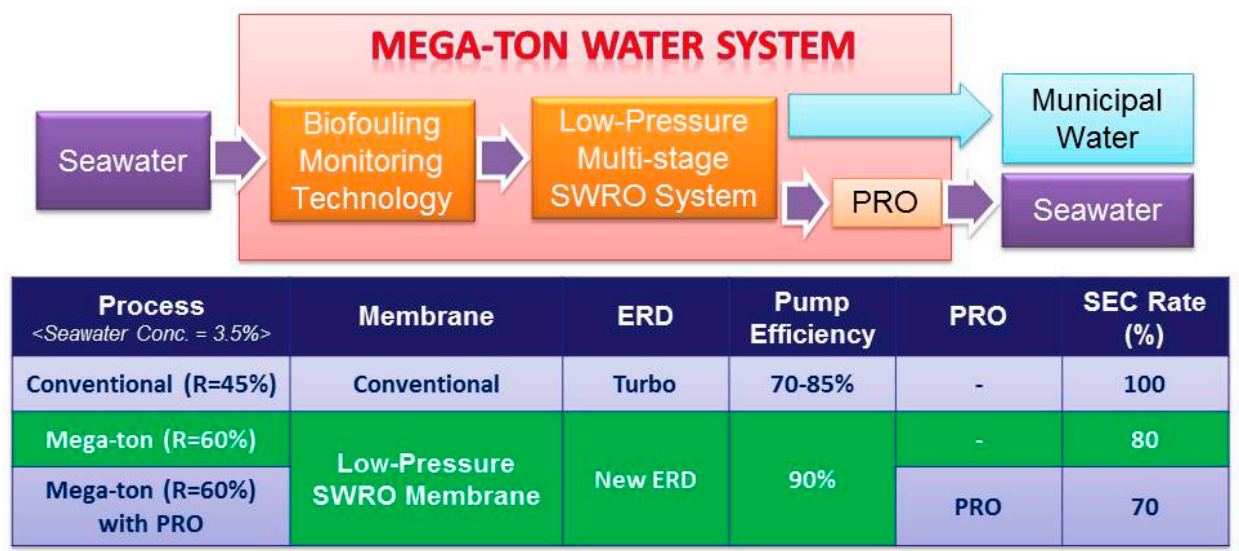

Figure 18. SEC Rate (\%) Comparison of conventional SWRO, Mega-ton SWRO and Mega-ton SWRO with PRO (SWRO-PRO).

The SWRO-PRO System of the "Mega-ton Water System" is near to being ready for adoption in commercial plants in the future. 
The authors found that the SWR-PRO system is also being studied in the Korea National Project and is being run in a pilot plant in Busan, Korea [25].

\section{Conclusions}

(1) There are three key challenges to developing sustainable desalination technologies that will be required in the 21st century: (1) energy saving; (2) low environmental impact; and (3) low water production cost. Solutions to these challenges are being developed through funding from the Japanese government "FIRST Program" in the "Mega-ton Water System" project.

(2) Innovative low-pressure SWRO membranes were obtained by controlled preparation technology based on a precise estimation of the protuberance of the membranes.

(3) As new membrane process technology, low-pressure multi-stage system (LMS), makes it possible to operate high recovery and low-pressure operation up to $60 \%$, which contributes to reducing the size of the plant and reducing the cost of low water production.

(4) Applying the various technologies in the "Mega-ton Water System" project to large-scale desalination plants would enable a $20 \%$ saving of energy consumption compared with commercialized systems.

(5) The SWRO-PRO system of the "Mega-ton Water System" allows 30\% energy saving compared with conventional systems. The SWRO-PRO system in the "Mega-ton Water System" can be commercialized with the development of a high performance $\left(13.3 \mathrm{~W} / \mathrm{m}^{2}\right)$ hollow fiber PRO membrane and system operation.

Acknowledgments: The "Mega-ton Water System" part of the research in this report is supported by the Japanese Society for the Promotion of Science (JSPS) through the "Funding Program for World-Leading Innovative R\&D on Science and Technology (FIRST Program)" initiated by the Council for Science and Technology Policy (CSTP). The author is deeply grateful to NEDO for supporting the "Mega-ton Water System" project.

Author Contributions: Masaru Kurihara conceived and designed the Project as the project leader; Hiromu Takeuchi promoted the Project as the secretary of the project; Masaru Kurihara and Hiromu Takeuchi wrote the paper.

Conflicts of Interest: The authors declare no conflict of interest.

\section{References}

1. International Desalination Association and Global Water Intelligence. DesalData 2014 Plant Inventory Report; Global Water Intelligence: Oxford, UK, 2014.

2. Kurihara, M.; Hanakawa, M. “Mega-ton Water System”: Japanese national research and development project on seawater desalination and wastewater reclamation. Desalination 2013, 308, 131-137. [CrossRef]

3. Lattemann, S.; Höpner, T. Environmental impact and impact assessment of seawater desalination. Desalination 2008, 220, 1-15. [CrossRef]

4. McCann, B.; Asano, T. Water21 Magazine; International Water Association: London, UK, 2011.

5. Kurihara, M.; Sasaki, T.; Nakatsuji, K.; Kimura, M.; Henmi, M. Low pressure SWRO membrane for desalination in the "Mega-ton Water System". Desalination 2015, 368, 135-139. [CrossRef]

6. Kurihara, M. Membrane research for water treatment facing the age of global mega competition \& collaboration, Oral Presentation in IUPAC World Polymer Congress Polymer and Polymer-based Membranes for Energy and Environmental Applications II. In Proceedings of the 2012 World Polymer Congress (WPC) of the International Union of Pure and Applied Chemistry (IUPAC), Blacksburg, VA, USA, 24-29 June 2012.

7. Kurihara, M.; Sasaki, T. The most advanced membrane analysis and the save-energy type: Low Pressure Seawater Reverse Osmosis Membrane developed by “Mega-ton Water System” Project. In Comprehensive Membrane Science and Engineering, 2nd ed.; Elsevier: Amsterdam, The Netherlands, 2017; Volume 4, pp. 131-149.

8. Sanz, M.A. Energy as Motor of Seawater Reverse Osmosis Desalination Development. In Proceedings of the Mega-ton Water System International Symposium, Tokyo, Japan, 21-22 November 2013. 
9. Kurihara, M.; Sasaki, T. The Pursuits of Ultimate Membrane Technology including Low Pressure Seawater Reverse Osmosis Membrane developed by “Mega-ton Water System" Project. J. Membr. Sci. Res. 2017, 3, 157-173.

10. Stover, R.L.; Andrews, B. Isobaric Energy Recovery Devices-Past, Present and Future, IDAWC/PER11-103. In Proceedings of the IDA World Congress, Perth, Australia, 4-9 September 2011.

11. Takahashi, T.; Shinoda, M.; Takita, S.; Goto, A. A Next-Generation Isobaric Energy Recovery Device with Piston-less and No-Leakage Concepts for SWRO Desalination, IDAWC/TIAN13-008. In Proceedings of the International Desalination Association World Congress, Tianjin, China, 20-25 October 2013.

12. Kurihara, M.; Yamamura, H.; Nakanishi, T. High recovery/high pressure membranes for brine conversion SWRO process development and its performance data. Desalination 1999, 125, 9-15. [CrossRef]

13. Wei, Q.; McGovern, R.; Lienhard, J.H.V. Saving energy with an optimized two-stage reverse osmosis system. Environ. Sci. Water Res. Technol. 2017, 3, 659-670. [CrossRef]

14. Wei, Q.; McGovern, R.; Lienhard, J. Two-stage reverse osmosis: Optimal element configuration and energy savings. In Proceedings of the IDA World Congress 2017, World Trade Center, Sao Paulo, Brazil, 19 October 2017.

15. Kishizawa, N.; Tsuzuki, K.; Hayatsu, M. Low pressure multi-stage RO system developed in "Mega-ton Water System" for large-scaled SWRO plant. Desalination 2015, 368, 81-88. [CrossRef]

16. Loeb, S. Method and Apparatus for Generation Power Utilizing Pressure-Retarded Osmosis. U.S. Patent 3906250, 16 September 1975.

17. Loeb, S. Method and Apparatus Generating Power Utilizing Pressure-Retarded Osmosis. U.S. Patent 4193267, 18 May 1980.

18. Loeb, S. Production of energy from concentrated brines by pressure-retarded osmosis. J. Membr. Sci. 1976, 1, 49-63. [CrossRef]

19. Loeb, S.; van Hessen, F.; Shahaf, D. Production of energy from concentrated brines by pressure-retarded osmosis: II. Experimental results and projected energy costs. J. Membr. Sci. 1976, 1, 249-269. [CrossRef]

20. Sarp, S. Pressure Retarded Osmosis (PRO): Current Statue and prospects. In Proceedings of the 2nd International Conference on Desalination Using Membrane Technology, Singapore, 26-29 July 2015.

21. Skilhagen, S.E.; Dugstad, J.E.; Aaberg, R.J. Osmotic power-Power production based on the osmotic pressure difference between waters with varying salt gradients. Desalination 2008, 220, 476-482. [CrossRef]

22. Kurihara, M.; Sakai, H.; Tanioka, A.; Tomioka, H. Role of pressure-retarded osmosis (PRO) in the mega-ton water project. Desalin. Water Treat. 2016, 57, 26518-26528. [CrossRef]

23. Tanioka, A.; Higa, M.; Sakai, H. Energy Recovery by Pressure Retarded Osmosis System. J. Membr. 2015, 40, 67-72. [CrossRef]

24. Saito, K. Power generation with salinity gradient by pressure retarded osmosis using concentrated brine from SWRO system and treated sewage as pure water. Desalin. Water Treat. 2012, 41, 114-121. [CrossRef]

25. Hong, S.; Kim, J.; Cha, G.; Kim, J. Low-energy seawater reverse osmosis (SWRO) desalination plant optimized for the Middle East. In Proceedings of the IDA World Congress 2017, World Trade Center, Sao Paulo, Brazil, 18 October 2017.

(C) 2018 by the authors. Licensee MDPI, Basel, Switzerland. This article is an open access article distributed under the terms and conditions of the Creative Commons Attribution (CC BY) license (http:/ / creativecommons.org/licenses/by/4.0/). 